\section{Socratic questions and frozen shoulders: teaching without telling}

\author{
John Launer
}

Not long ago, I was asked to teach Socratic questioning to some doctors specialising in accident and emergency medicine. This might seem like a strange piece of work to take on. Doctors in emergency medicine commonly work fast and under great pressure. They have to recall and apply factual knowledge at speed, and to teach their trainees to do the same. Socratic questioning, by contrast, is a way of teaching that depends on slowing things down. Named after the Greek philosopher Socrates, the method rests on the assumption that people gain a fuller understanding of a problem if they work out each stage of the answer for themselves. ${ }^{1}$ Teachers therefore avoid asking any leading questions, offering direct information, or confronting students openly with their ignorance. Instead, they use a progression of open questions to help students think about any problem logically. A typical series of Socratic questions from a clinical teacher might be: 'What explanations could account for these symptoms?", 'Which seems the most likely cause?", 'Why do you think so?' and 'How would you establish that for certain?'

I was teaching the emergency doctors with a colleague who was not herself a doctor but a professional educator. We knew it would be hard for them to use Socratic questions in the hurly-burly of their everyday work, but we wanted to show how there might be a place for these in more relaxed moments, for example in case discussions before or after seeing patients. We expected there might be some scepticism, and were not surprised when one of the participants challenged us quite early on, saying that he could see absolutely no place for such an approach in his work, or in any specialty that depended on simply 'telling trainees the facts.' I asked him for an example of a condition he thought it would be quite impossible to teach through using Socratic questions. For some reason, he named frozen shoulders. Unwittingly, he had provided us with the best possible opportunity for demonstrating why Socratic questions are a powerful and effective form of teaching.

Correspondence to Dr John Launer, Health Education England, London WC1B 5DN, UK; johnlauner@aol.com
I asked my colleague permission to use her as a guinea pig for exploring the possibilities and limits of Socratic questions in a 'factual' condition such as this, and she agreed. She warned me she knew 'absolutely nothing' about shoulders, frozen or otherwise. I then inquired if she had ever known anybody who had suffered from one or - alternatively - if she could imagine what the term might mean. She said she vaguely remembered someone, a relative possibly, who was troubled by a frozen shoulder for a year or two. She also instinctively began to move one of her shoulders around, presumably to stimulate the memory of that person but also to inhabit the experience imaginatively.

\section{INTELLIGENT GUESSES}

My next question was whether she could guess what the symptoms of the condition might be, given its name. 'Stiffness', she suggested, 'and pain. Maybe that's what frozen means - not being able to move it in any direction without it hurting.' I confirmed her hunch and asked her what the causes might be. She ventured some more intelligent guesses: an injury like a fall, perhaps, or sometimes just coming out of the blue as you got older. Again, I told her she was right. I then invited her to feel one of her own shoulders with her other hand. Without explaining anything to her, I guided her with a series of questions to discover how it was constructed and how it functioned. She managed to work out that it was a kind of socket, with the collar bone joining it from the side and the upper arm hanging down below. By trying to reach in every direction, she then found out that her arm could flex, extend, rotate, adduct and abduct, as well as combining some of these movement to touch her upper lumbar spine with her thumb. She had independently discovered Apley's test, one of the most useful diagnostic procedures for the condition. ${ }^{2}$

Next, I asked her to carry out an examination of my shoulder too, based on what she had learnt about her own, and to tell me what she thought. She found that my own movements, possibly because of my age, did not quite have as much range as hers, although it was clearly not frozen. As the final part of the experiment, I asked if she could hazard a guess at possible ways of treating a frozen shoulder once it was established. 'Exercises? Physiotherapy? Surgery, if it's really bad?' She also tentatively mentioned steroid injections, which she had heard about in another context. Without any prompting, and without a day's medical training in her life, she had named every modality of treatment in current use for the syndrome.

By the end of the demonstration, she had not only deduced a tremendous amount of accurate information about frozen shoulders - with no didactic input from me. She had also put herself in a position to teach others about the subject in future, either by direct teaching or, as I had done, by Socratic questioning alone. If I had just told her about frozen shoulders or, even worse, grilled her aggressively about them in a way that exposed and humiliated her (a process that is sometimes nicknamed 'pimping'), ${ }^{3}$ she would not have achieved a fraction of the learning.

\section{BRINGING FORTH UNDERSTANDING}

In some ways I was lucky. My 'trainee' was quick-witted and imaginative. The condition was a simple, anatomical one. If the person challenging us had suggested something more complex and physiological like diabetic ketoacidosis, we would not have had an easy time. On the other hand, I was questioning someone without any formal medical knowledge. The emergency doctors had the advantage of working with juniors with many years of prior training and an advanced capacity to infer technical facts from basic principles. Their teachers could be far more adventurous in trying to 'bring forth' their trainees' actual or potential understanding in just about any illness, rather than perpetually trying to 'put it in.' My colleague and I had made our point.

What was I not able to cover by this approach? The answer, of course, is evidence-based treatment. No amount of 'bringing forth' could have established which of the different treatments was best in terms of evidence. Yet even here, the matter is not as straightforward as you might think. In the case of frozen shoulders, for example, the evidence base for the various kinds of treatments is actually rather slim, as it is in so many other conditions. Different rheumatologists, orthopaedic surgeons and physiotherapists do indeed use each of the treatments my colleague mentioned, but largely as a matter of individual preference, and with little scientific basis. As one review of the subject has put it: 'Several treatment options are 
commonly used, but few have high-level evidence to support them.' ${ }^{\text {' Observa- }}$ tion and reassurance may in fact be as good as anything else. Ironically, if I had asked my colleague about best practice in treating frozen shoulders and she had replied 'I haven't a clue', she would have been answering in a way that represented the current state of knowledge as accurately as anyone else could have done.

This draws attention to another, less commonly emphasised benefit of using Socratic questioning. Faced with open but encouraging questions, and obliged to work everything out for themselves, learners generally respond with an attitude of thoughtfulness, hesitancy and humility, just as my colleague did. They become clearer about what they know and what they are uncertain about. Perhaps even more important, they become more curious and reflective about what is known medically about a particular subject, and what remains a matter of conjecture or controversy. Socratic questioning holds both individual and collective knowledge up to the light, affirming its validity when correct, and exposing its limitations when it is not. As such, it goes to the heart of the scientific method. In the words of one writer on Socratic questions: "Every intellectual field is born out of a cluster of questions to which answers are either needed or highly desirable. Furthermore, every field stays alive only to the extent that fresh questions are generated and taken seriously as the driving force in a process of thinking. ${ }^{4}$

\section{Twitter Follow John Launer @JohnLauner}

Acknowledgements I would like to thank Christine Young for participating in the educational experiment described here.

Competing interests None declared.

Provenance and peer review Commissioned; internally peer reviewed.
(C) Article author(s) (or their employer(s) unless otherwise stated in the text of the article) 2017. All rights reserved. No commercial use is permitted unless otherwise expressly granted.

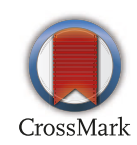

To cite Launer J. Postgrad Med J 2017;93:783-784.

Postgrad Med J 2017;93:783-784.

doi:10.1136/postgradmedj-2017-135415

\section{REFERENCES}

1 Elder L, Paul R. The role of socratic questioning in thinking, teaching, and tearning. The Clearing House: $A$ J Edu Strat, Issues and Ideas 1998;71:297-301.

2 Ewald A. Adhesive capsulitis: a review. Am Fam Phys 2011;83:417-22.

3 Kost A, Chen FM. Socrates was not a pimp: changing the paradigm of questioning in medical education. Acad Med 2015;90:20-4.

4 The Critical Thinking Community. The role of socratic questioning in thinking, teaching, and learning. http:// www. criticalthinking.org/pages/the-role-of-socraticquestioning-in-thinking-teaching-amp-learning/522 (accessed 23 Oct 2017). 